\title{
openheart Effects of spirulina on weight loss and blood lipids: a review
}

\author{
James J DiNicolantonio (D) , ${ }^{1}$ Anusha G Bhat, ${ }^{2,3}$ James OKeefe (i) ${ }^{4}$
}

To cite: DiNicolantonio JJ, Bhat AG, OKeefe J. Effects of spirulina on weight loss and blood lipids: a review. Open Heart 2020;7:e001003. doi:10.1136/ openhrt-2018-001003

Accepted 19 February 2020

Check for updates

(c) Author(s) (or their employer(s)) 2020. Re-use permitted under CC BY-NC. No commercial re-use. See rights and permissions. Published by BMJ.

${ }^{1}$ Mid America Heart Institute, Kansas, Kansas, USA ${ }^{2}$ Department of Internal Medicine, Baystate Medical Center, Springfield, Massachusetts, USA

${ }^{3}$ Department of Public Heath Practice, School of Public Health and Health Sciences, University of Massachusetts, Amherst, Massachusetts, United States ${ }^{4}$ Saint Lukes Mid America Heart Institute, University of MissouriKansas City, Kansas City, Missouri, USA

Correspondence to Dr James J DiNicolantonio; jjdinicol@gmail.com

\section{ABSTRACT}

Spirulina, a cyanobacteria commonly referred to as a blue-green algae, is one of the oldest lifeforms on Earth. Spirulina grows in both fresh and saltwater sources and is known for its high protein and micronutrient content. This review paper will cover the effects of spirulina on weight loss and blood lipids. The currently literature supports the benefits of spirulina for reducing body fat, waist circumference, body mass index and appetite and shows that spirulina has significant benefits for improving blood lipids.

\section{INTRODUCTION}

Spirulina is both a salt and fresh water bluegreen algae, which is being increasingly studied recently. Spirulina was initially classified under the plant kingdom due to its rich plant pigments and its ability to photosynthesize, but was later placed into bacterial kingdom (cyanobacteria) due to its genetic, physiological and biochemical makeup. ${ }^{1}$ Spirulina grows naturally in high salt alkaline water reservoirs in subtropical and tropical areas of America, Mexico, Asia and Central Africa. ${ }^{1}$

Among the many varieties of spirulina, the most commonly studied species are Spirulina platensis (Arthrospora platensis), Spirulina maxima (Arthrospora maxima) and Spirulina fusiformis (Arthrospora fusiformis). Spirulina is composed of numerous antioxidants, including beta-carotene, phycocyanin, tocopherols, micronutrients, polyunsaturated fatty acids, particularly gamma-linolenic acid and phenolic compounds. The high nutritive values of spirulina were recognised by the Intergovernmental Institution for the use of Microalgae Spirulina Against Malnutrition in the 1970s, where they launched Spirulina to fight against starvation and malnutrition. ${ }^{2}$ Spirulina has also been recognised and recommended by National Aeronautics and Space Administration and the European Space Agency for food supplementation during long-term space travels. Since then, there have been numerous animal and human clinical trials to determine its beneficial effects as a supplement. Spirulina is a low-cost nutritional supplement and has not been established to have any significant side effects. Metabolic syndrome is currently on rise ${ }^{3}$ and dyslipidaemia and obesity are an integral component of its causation. While there are several other supplements being evaluated for lipid lowering and weight loss effects, benefits from supplementation of spirulina are not limited to the above benefits but also extends to its antiviral, anticancer, antioxidant, antidiabetic, anti-inflammatory, hepatoprotective, cardioprotective and immunity boosting properties. ${ }^{45}$ The primary aim of this article is to review the effects of spirulina on obesity and dyslipidaemia. Additionally, we also discuss the potential mechanism of action for the aforementioned effects.

\section{Anti-inflammatory effects of spirulina}

The prevalence of obesity has nearly tripled since $1975 .^{6}$ According to the 2016 global health report, more than 1.9 billion adults were categorised as overweight; 650 million among them being obese. ${ }^{7}$ Globally, approximately 2.8 million adults are estimated to die every year from it. ${ }^{8}$ Obesity has been closely linked to inflammation, hyperlipidaemia and insulin resistance. ${ }^{9}{ }^{10}$ This may be due to the fact that adipose tissue secretes numerous biologically active substances like adipokines and chemokines, which play an important role in inflammation and the development of atherosclerosis. $^{11}$

Although caloric restriction and exercise are the mainstay treatments for obesity, spirulina has shown significant benefits in aiding weight loss. The phycocyanin in spirulina contains a light-harvesting chromophore called phycocyanobilin, which is capable of inhibiting nicotinamide adenine dinucleotide phosphate hydrogen (NADPH) oxidase, a significant source of oxidative stress in adipocytes playing a key role in inducing insulin resistance and shifting adipokine and cytokine production in hypertrophied adipocytes. Thus, by suppressing adipocyte 
oxidative stress, spirulina may lead to systemic antiinflammatory and insulin-sensitising effects. ${ }^{12-20}$

\section{Weight loss and blood lipids}

Several clinical and preclinical trials have been conducted to test the benefits of spirulina on weight loss. Yousefi et al studied 52 obese participants with a body mass index $(\mathrm{BMI}) \geq 25-40 \mathrm{~kg} / \mathrm{m}^{2}$ who were randomised to $2 \mathrm{~g}$ spirulina per day with a restricted caloric diet versus placebo consisting of a restricted calorie diet for 12 weeks. Participants in the spirulina group had significantly lower body weight of $-3.22+1.97 \mathrm{~kg}$, waist circumference $-3.37 \pm 2.65 \mathrm{~kg}$, body fat of $-2.28+1.74 \mathrm{~kg}$ and BMI of $-1.23 \pm 0.79 \mathrm{~kg} / \mathrm{m}^{2}(\mathrm{p}<0.001, \mathrm{p}=0.049, \mathrm{p}=0.049$ and $\mathrm{p}=0.02$, respectively). Additionally, triglycerides (TG) reduced by $-18 \mathrm{mg} / \mathrm{dL}$ and high-sensitivity $\mathrm{C}$ reactive protein levels were lower by $-1.66 \pm 1.9 \mathrm{ng} / \mathrm{mL}$ towards the end of the study period ( $\mathrm{p}=0.03$ and $\mathrm{p}=0.02$, respectively). ${ }^{21}$

Zeinalian et al studied 62 obese subjects after administering $1 \mathrm{~g}$ spirulina for 12 weeks and observed a significant reduction in appetite by $-4.16 \%(\mathrm{p}=0.008)$, BMI by $-1.9 \% \quad(p<0.001)$, body weight by $-1.79 \% \quad(p<0.001)$ and a reduction in total cholesterol (TC) by $-4.67 \%$ $(p=0.002){ }^{22}$ Additionally, high density lipoproteincholesterol (HDL-C) was noted to increase by $1.73 \%$ $(\mathrm{p}=0.05)$ with no significant change in TG or low density lipoprotein (LDL).

Several trials have also used Spirulina maxima to assess its beneficial effects. In one study, 50 obese subjects with hypertension under antihypertensive treatment were given $2 \mathrm{~g}$ spirulina per day or placebo for 3 months. Those given spirulina were found to have significant improvements in their body mass from $92.96 \pm 18.58 \mathrm{~kg}$ to $88.97 \pm 17.13 \mathrm{~kg} \quad(\mathrm{p}<0.001)$, BMI from $33.5+6.7 \mathrm{~kg} / \mathrm{m}^{2}$ to $31.7 \pm 5.8 \mathrm{~kg} / \mathrm{m}^{2}(\mathrm{p}<0.001)$ and waist circumference from $105.2 \pm 15.3$ to $103.4+14.1 \mathrm{~cm}(\mathrm{p}<0.002)$ versus baseline, a benefit that was not shown with the placebo. Compared with placebo-treated individuals, those given spirulina had significantly lowered LDL-cholesterol (LDL-C) from $3.5+0.9 \mathrm{mmol} / \mathrm{L}$ to $3.0 \pm 0.6 \mathrm{mmol} / \mathrm{L}(\mathrm{p}<0.001)$ and interleukin-6 from $4.3 \pm 0.6 \mathrm{mmol} / \mathrm{L}$ to $3.9+0.4 \mathrm{mmol} / \mathrm{L}$ $(\mathrm{p}=0.002)$ and improved total antioxidant status from $1.8 \pm 0.3$ to $2.2 \pm 1.0 \mathrm{mmol} / \mathrm{L}(\mathrm{p}=0.001)$ and insulin sensitivity ratio from $3.2 \pm 1.8 \mathrm{mg} / \mathrm{kg} / \mathrm{min}$ to $4.3 \pm 2.1 \mathrm{mg} / \mathrm{kg} /$ $\min (\mathrm{p}<0.001){ }^{23}$

Mizcke et al in 2016 demonstrated benefits of spirulina maxima in 40 hypertensive patients without evidence of cardiovascular disease when supplemented with $2 \mathrm{~g}$ of spirulina per day versus placebo for 3 months. In those given spirulina, there was significant reduction in BMI (26.9 \pm 3.1 vs $\left.25.0 \pm 2.7 \mathrm{~kg} / \mathrm{m}^{2}, \mathrm{p}=0.0032\right)$, weight $(75.5 \pm 11.8 \mathrm{~kg}$ vs $70.5 \pm 10.3 \mathrm{~kg}, \mathrm{p}<0.001)$, systolic blood pressure $(149 \pm 7 \mathrm{~mm} \mathrm{Hg}$ vs $143 \pm 9 \mathrm{~mm} \mathrm{Hg}, \mathrm{p}=0.0023)$ and arterial stiffness index $(7.2 \pm 0.6$ vs $6.9 \pm 0.7 \mathrm{~m} / \mathrm{s}, \mathrm{p}<0.001)$, thus proving beneficial cardiovascular effects with shortterm low-dose spirulina supplementation (table 1). ${ }^{24}$

\section{BLO0D LIPIDS}

\section{Animal studies}

Spirulina has been speculated to have lipid lowering capabilities since $1981 .^{25}$ Hypocholesterolaemic effect was initially shown in animal trials. ${ }^{26}$ Later in 1990, Iwata et al conducted the first preclinical trial on young and healthy Wistar rats, which were artificially induced with hyperlipidaemia by feeding a high-fructose diet. The groups were either on high fructose diet alone $(68 \%)$ or on high-fructose diet with spirulina at 5\%, 10\% and 15\% concentrations for 4 weeks. Towards the end of the study period, blood samples were obtained after administration of intravenous heparin injection at the dose of 200 $\mathrm{U}$ per $100 \mathrm{~g}$ body weight. The results revealed a significant improvement in the lipid profile with concomitant increased activity of lipoprotein lipase (LPL), although the difference in lipid levels or LPL was not significantly different between $5 \%, 10 \%$ or $15 \%$ spirulina concentration groups. ${ }^{27}$

The hypolipaemic effect of spirulina was also shown in artificially induced diabetes in mice with administration of alloxan $(250 \mathrm{mg} / \mathrm{kg}$ body weight). With administration of $5 \%$ spirulina, hepatic triacylglycerols decreased. Improvement in serum HDL and lowered serum LDL as well as VLDL was also noted. ${ }^{28}$

Li et al found that spirulina given for 8 weeks increased HDL-C and lowered LDL-C, TG and TC levels when fed a high fat diet. ${ }^{29}$ Similar to other previous studies, it was also shown to normalise hepatic steatosis with improvements in liver function tests, including transaminases, free fatty acids and overall lipid profile. This action was thought to be secondary to activation of AMP-activated protein kinase signalling pathway which subsequently downregulates the expression of lipid synthesising genes, namely sterol regulatory element-binding transcription factor-1c, 3-hydroxy-3-methyl glutaryl coenzyme A reductase and acetyl CoA carboxylase which ultimately reduce TG levels and subsequently inhibit synthesis of fatty acids.

Additionally, spirulina can alter gut microbiota to have lipid lowering effects. Studies have revealed an increase in abundance of Prevotella, Porphyromonadaceae, Barnesiella and Paraprevotella. Prevotella increases bile metabolism to reduce blood lipid levels. Alloprevotella and Ruminococcus are short chain fatty acid producers which can be digested by the intestine. They regulate energy metabolism and improve insulin sensitivity via specific receptors to ultimately reduce lipid metabolism disorders and prevent non-alcoholic liver disease. Firmicutes are another group of bacteria which have been associated with reduction in body weight and serum LDL-C levels, which improved with spirulina supplementation. ${ }^{29}$

\section{Clinical trials}

The clinical trials on humans using spirulina include healthy patients and those with dyslipidaemia, hypertension, postischaemic heart disease, diabetes, the nephrotic syndrome and elderly patients. The response to spirulina supplementation has been noted to differ between 


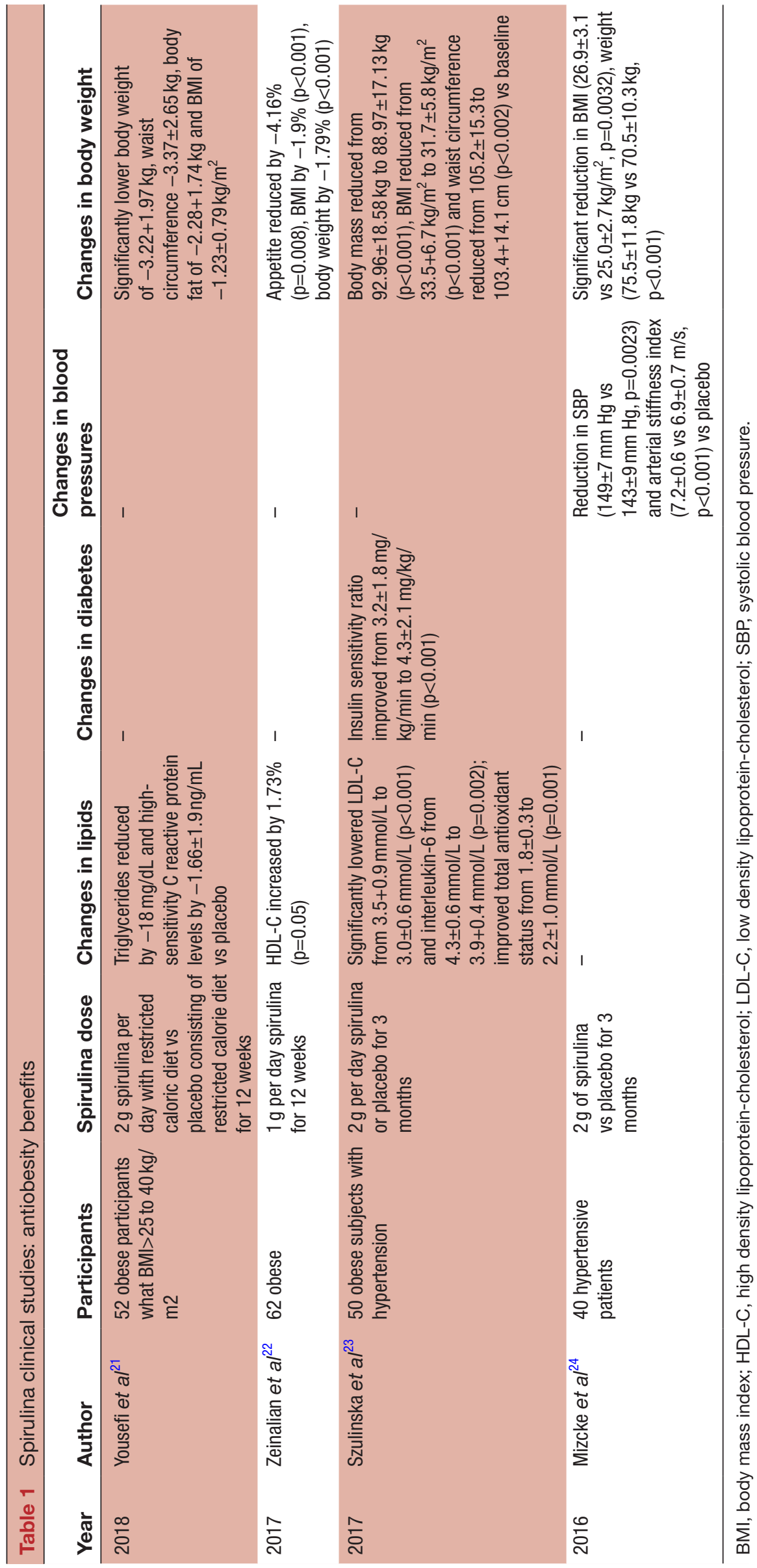




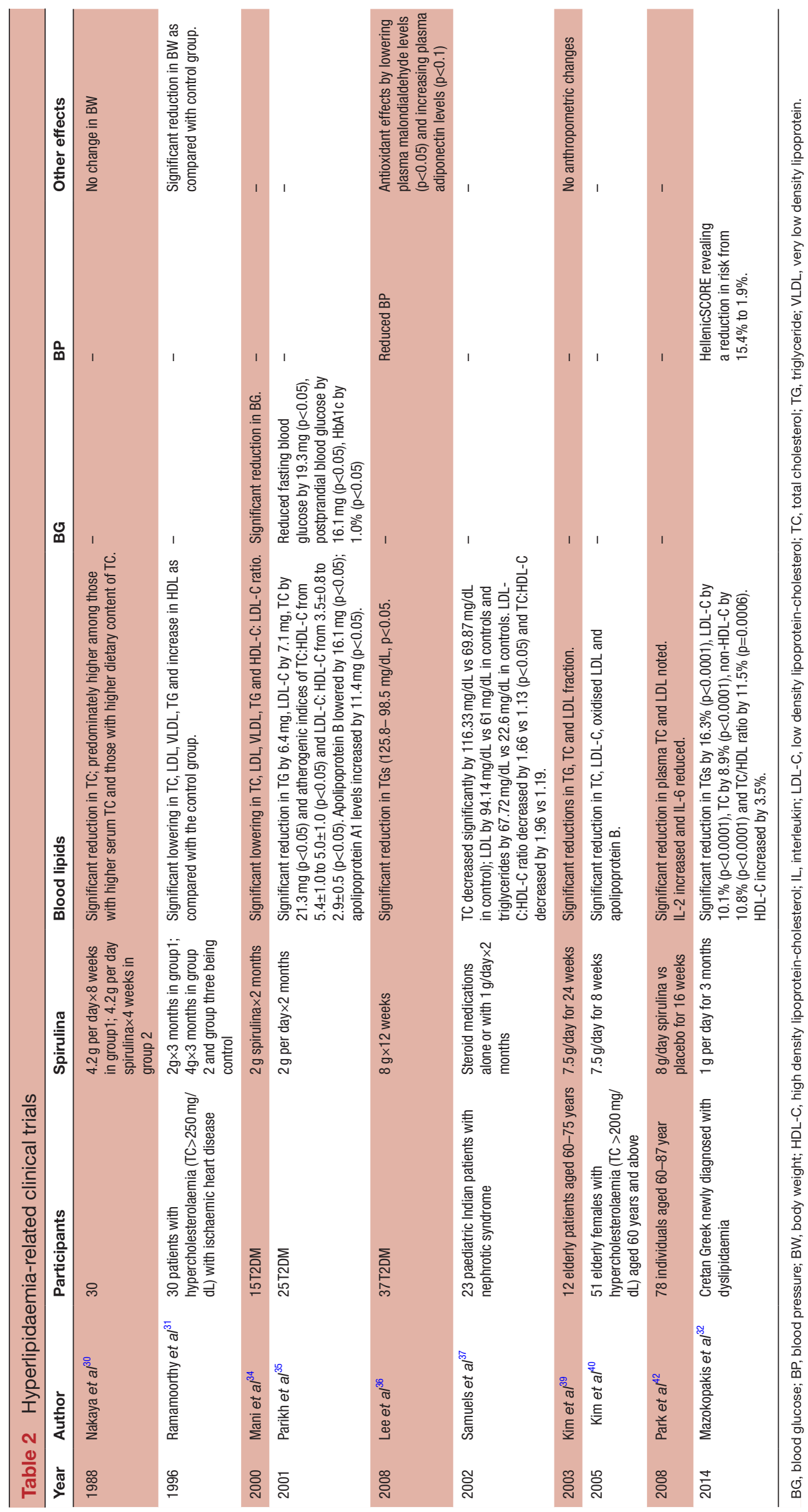


different ages, races, genders, comorbidities and dose/ duration of treatment.

One of the first clinical trials ever done using spirulina was carried out in 1988 consisting of 30 healthy volunteers with mild hypertension or hyperlipidaemia. They were treated in two groups, one of the groups received 8 weeks of $4.2 \mathrm{~g}$ of spirulina versus the other group which received the same amount of spirulina for 4 weeks followed by observation for another 4 weeks without any supplementation. Results were notable for a significant reduction in TC in the initial 4 weeks of spirulina supplementation, which returned to baseline with its discontinuation. These changes in $\mathrm{TC}$ were directly proportional to serum TC and dietary TC concentrations. There were no changes in HDL, TG or body weight. ${ }^{30}$

Ramamoorthy et al established the hypolipaemic effects of spirulina in patients with ischaemic heart disease and hypercholesterolaemia (serum cholesterol levels $>250 \mathrm{mg} / \mathrm{dL}$ ), where a total of 30 patients were spilt into three groups. Groups 1 and 2 were treated with $2 \mathrm{~g}$ or $4 \mathrm{~g}$ of spirulina for 3 months, while group 3 was a control arm. Towards the end of the study period, plasma TC was lowered by $22.4 \%$ and $33.5 \%$ in group 1 and 2, respectively $(\mathrm{p}<0.01)$ and LDL by $31 \%$ and $45 \%$ $(\mathrm{p}<0.01)$, which were both statistically significant reductions. Higher reductions in both LDL and TC were noted among those treated with $4 \mathrm{~g}$ spirulina/day. In addition, HDL-C increased, while TG and VLDL decreased in both the experimental groups. However, there was no statistical significance between the two experimental groups while there was significant change when compared with the control group. Similarly, body weight was reduced in both the treatment groups while there were no changes in lipid profiles or body weight in the control arm. The reduction in body weight in both groups given spirulina $(-2.2 \mathrm{~kg})$ was highly significant compared with control $(0.7 \mathrm{~kg} ; \mathrm{p}<0.01)$. $^{31}$

Supplementation of $1 \mathrm{~g}$ spirulina for 3 months among Cretan Greek patients with newly diagnosed dyslipidaemia also revealed significant improvements in dyslipidaemia. Mean levels of TGs reduced by $16.3 \%(\mathrm{p}<0.0001)$, LDL-C by $10.1 \%(\mathrm{p}<0.0001)$, TC by $8.9 \%(\mathrm{p}<0.0001)$, non-HDL-C by $10.8 \%(\mathrm{p}<0.0001)$ and $\mathrm{TC} / \mathrm{HDL}$ ratio by $11.5 \%(\mathrm{p}=0.0006)$. Additionally, HDL-C increased by $3.5 \%$, without any significant changes in weight, BMI or blood pressures. ${ }^{30}$ The TG levels reduced by $17.2 \%$ on an average; the reduction was higher (at 21.3\%) among women over 47 years old and those with TG>150 mg/dL ( $18.6 \%$ reduction). HellenicSCORE is a scoring system designed to assess risk for development of cardiovascular disease and associated mortality among the Greek population, and the overall cardiovascular risk level on HellenicSCORE in this study projected a reduction in risk from $15.4 \%$ to $1.9 \%$ during the study period..$^{32} 33$

In 15 patients with non-insulin dependent diabetes mellitus, supplementation of $2 \mathrm{~g}$ /day of spirulina for 2 months leads to significant reductions in TG, TC, LDL-C, VLDL-C and LDL-C/ HDL-C ratio. ${ }^{34}$ Similarly, Parikh et al enrolled 25 type 2 diabetics and established that $2 \mathrm{~g}$ / day of spirulina for 2 months in this population can lower fasting blood glucose by $19.3 \mathrm{mg}(\mathrm{p}<0.05)$, postprandial blood glucose by $16.1 \mathrm{mg}(\mathrm{p}<0.05)$, HbAlc by $1.0 \%$ $(\mathrm{p}<0.05)$ in addition to lowering in TG by $6.4 \mathrm{mg}$, LDL-C by $7.1 \mathrm{mg}$, TC by $21.3 \mathrm{mg}(\mathrm{p}<0.05)$ and overall reduction in atherogenic indices of TC:HDL-C from $5.4 \pm 1.0$ to $5.0 \pm 1.0 \quad(\mathrm{p}<0.05)$ and LDL-C: HDL-C from $3.5 \pm 0.8$ to $2.9 \pm 0.5 \quad(\mathrm{p}<0.05)$. Additionally, apolipoprotein $\mathrm{B}$ was lowered by $16.1 \mathrm{mg}(\mathrm{p}<0.05)$ with subsequent increases in apolipoprotein A1 levels by $11.4 \mathrm{mg}(\mathrm{p}<0.05)$, thus a favourable increase in A1:B ratio. However, the increase in apo B levels with reduction in apo A1 level was also significant among the control group. Nevertheless, this study was able to establish improved short-term control from spirulina on glucose and lipid profiles among diabetics. ${ }^{35}$

Lee et al in 2008 tested $8 \mathrm{~g} /$ day of spirulina on 37 Korean subjects with T2DM (Type 2 diabetes mellitus) for 12 weeks, which resulted in a significant reduction in TGs $(125.8-98.5 \mathrm{mg} / \mathrm{dL}, \mathrm{p}<0.05)$. Those with higher plasma TG showed greater reductions in TG levels. Similarly, the subjects with higher TC and LDL-C levels showed greater reductions in TC, LDL-C and improvement in blood pressure. The study also revealed lowering in plasma malondialdehyde levels $(\mathrm{p}<0.05)$ and increased plasma adiponectin levels $(\mathrm{p}<0.1)$, which are indicative of a reduction in oxidative stress with spirulina supplementation. ${ }^{36}$

Dyslipidaemia is a common comorbidity in patients with nephrotic syndrome. Loss of plasma proteins in the urine can cause low oncotic pressure, which leads to hepatic production of albumin and other proteins including lipoproteins, which can contribute to hyperlipidaemia. In this study, 23 paediatric patients with hypercholesterolaemia and nephrotic syndrome, between the age of 2 and 13 years were treated with steroid medications alone or in combination with $1 \mathrm{~g} /$ day spirulina for 2 months. At the end of study period, TC decreased by $116.33 \mathrm{mg} / \mathrm{dL}$ vs $69.87 \mathrm{mg} / \mathrm{dL}$ in control; LDL by $94.14 \mathrm{mg} / \mathrm{dL}$ vs $61 \mathrm{mg} / \mathrm{dL}$ in controls and triglycerides by $67.72 \mathrm{mg} / \mathrm{dL}$ vs $22.6 \mathrm{mg} / \mathrm{dL}$ in controls. LDL-C:HDL-C ratio decreased significantly by 1.66 vs $1.13(\mathrm{p}<0.05)$ and TC:HDL-C decreased by 1.96 vs 1.19 . Thus, the overall findings concluded that spirulina has significant hypolipidaemic effects in patients with nephrotic syndrome. ${ }^{37}$

Hyperlipidaemia and coronary vascular disease (CVD) are known to increase with advancing age. ${ }^{38}$ Most of the clinical trials testing spirulina supplementation on the elderly population has been in Korea. One study included 12 Korean patients between the age 60 and 75 years old who were supplemented with $7.5 \mathrm{~g} /$ day of spirulina for 24 weeks. The study found significant reductions in TGs, TC and LDL after 4 weeks of spirulina supplementation. There was no difference in the reduction among patients with mild hypercholesterolaemia (TC at or above $200 \mathrm{mg}$ / dL) vs normocholesterolaemia. ${ }^{39}$ In 2005 , another study involved 51 elderly females with hypercholesterolaemia 
( $\mathrm{TC}>200 \mathrm{mg} / \mathrm{dL}$ ) aged 60 years and above, where they were supplemented with $7.5 \mathrm{mg} /$ day spirulina for 8 weeks in half of the study population and the other half were given placebo. Findings were significant for reductions in TC, LDL-C, oxidised LDL and apolipoprotein B ${ }^{40}$ The most recent randomised controlled trial included 78 individuals aged $60-87$ years, who were randomly assigned to $8 \mathrm{~g} /$ day spirulina versus placebo for 16 weeks. The female were noted to have higher mean TC and LDL-C and also showed significant reductions in their plasma levels, TC from 200.5 to $184.8 \mathrm{mg} / \mathrm{dL}$ ( $\mathrm{p}=0.03$ ) and LDL from 126.7 to $112.1 \mathrm{mg} / \mathrm{dL}(\mathrm{p}=0.05){ }^{41}$ In addition, interleukin-2 (IL-2) was significantly increased $(\mathrm{p}<0.0001)$ and IL-6 was reduced $(\mathrm{p}<0.05)$ at the end of the study period. IL-2 has anti-inflammatory properties and is an important regulator of chronic inflammatory response. IL-2 levels reduce with increasing age; thus, supplementation with spirulina may help to boost immunity in the elderly. ${ }^{42}$

A systematic review published in 2015 encompassing eight humans studies concluded that spirulina has blood lipid lowering benefits and antioxidant effects. ${ }^{43}$ Furthermore, a recent 2018 meta-analysis of 12 clinical studies in humans showed that spirulina supplementation $(1 \mathrm{~g}$ up to $19 \mathrm{~g}$ per day) significantly lowered TC $(-36.60 \mathrm{mg} /$ $\mathrm{dL} ; \mathrm{p}=0.0001)$, low-density lipoprotein cholesterol $(-33.16 \mathrm{mg} / \mathrm{dL} ; \quad \mathrm{p}=0.0002)$, triglycerides $(-39.2 \mathrm{mg} /$ $\mathrm{dL} ; \mathrm{p}=0.0001)$, very-low-density lipoprotein cholesterol $(-8.02 \mathrm{mg} / \mathrm{dL} ; \mathrm{p}=0.0001)$, fasting blood glucose $(-5.01 \mathrm{mg} / \mathrm{dL} ; \mathrm{p}=0.04)$ and diastolic blood pressure $(-7.17 \mathrm{~mm} \mathrm{Hg} ; \mathrm{p}=0.001){ }^{41}$

Overall, the evidence in the literature suggests that spirulina improves several well-established CVD risk factors including hyperlipidaemia and seems to provide benefits around weight loss. The variation in response in the clinical trials is likely due to the difference in dose, duration of treatment and responsiveness among patients based on their comorbidities. As a whole, supplementing spirulina at $2-8 \mathrm{~g}$ / day may improve lipid profiles, particularly by reducing TC, TG and LDL-c and improving HDL-c; improving apolipoprotein A1 and reducing apolipoprotein B, aiding weight loss and reducing BMI. Spirulina also seems to improve insulin resistance, antioxidant/ anti-inflammatory properties, blood glucose and blood pressure as discussed in this article (table 2).

\section{SUMMARY OF THE MECHANISMS OF ACTION OF SPIRULINA}

- Faecal excretion of cholesterol and bile: In 2005, Nagoaka et al demonstrated lower micellar solubility of cholesterol with bile acids and as a result reduced absorption of fats in the small intestine with higher faecal excretion of cholesterol and bile acid when fed with spirulina concentrates. Additionally, phycocyanin residue diet increased the proportion of cholesterol excretion, thus indicating the hypolipaemic effects of spirulina, particularly from phycocyanin. ${ }^{44}$

- Anti-inflammatory properties: Reactive oxygen species are frequently associated with tissue inflammation and damage. Due to Spirulina's composition of the blue-green pigments, particularly phycocyanobilin, a water-soluble photosynthetic pigment possessing extensive anti-inflammatory and antioxidant properties. Phycocyanobilin is structurally similar to bilirubin and can inhibit NADPH oxidase. The antioxidant activity of spirulina has been proven to be directly proportional to the quantity of phycocyanin (which contains phycocyanobilin). ${ }^{12-14} 45$

- Weight loss: The proposed mechanism of action of spirulina is a reduction in macrophage infiltration into visceral fat, prevention of hepatic fat accumulation, reduction in oxidative stress, improvement in insulin sensitivity and satiety.

- Improves satiety: Reduction in appetite may be due to an improvement in leptin resistance in the arcuate nucleus.

- Pancreatic lipase inhibition: One of the components of spirulina is noted to be glycolipid H-b2, which inhibits pancreatic lipase activity in a dose depended way, thus reducing postprandial TG levels. ${ }^{46}$ Similar effects may be exerted by phycocyanin as well. ${ }^{46}$

- Prevention of cholesterol accumulation by gamma-linolenic acid: Spirulina is also composed of gamma-linolenic acid (GLA). GLA is mostly formed from conversion of LA in the presence of enzyme delta-6-desaturase, which may be inhibited with mineral deficiencies, alcohol/tobacco abuse, infections, ageing and other severe medical conditions. Moreover, GLA deficiencies may worsen arterial thickness, hypertension and dyslipidaemia. ${ }^{478}$ Additionally, spirulina also contains vitamin B3, also called niacin, which is also known to improve dyslipidaemia. ${ }^{49}$

Overall, spirulina has several benefits for improving weight loss, dyslipidaemia and obesity. However, further research including larger clinical trials would be warranted for confirming these benefits.

Contributors All authors contributed to the final manuscript.

Funding The authors have not declared a specific grant for this research from any funding agency in the public, commercial or not-for-profit sectors.

Competing interests JJD is the author of The Salt Fix and Superfuel. J0 is owner of a nutraceutical company but the company does not sell spirulina.

Patient consent for publication Not required.

Provenance and peer review Not commissioned; externally peer reviewed.

Open access This is an open access article distributed in accordance with the Creative Commons Attribution Non Commercial (CC BY-NC 4.0) license, which permits others to distribute, remix, adapt, build upon this work non-commercially, and license their derivative works on different terms, provided the original work is properly cited, appropriate credit is given, any changes made indicated, and the use is non-commercial. See: http://creativecommons.org/licenses/by-nc/4.0/.

ORCID iDs

James J DiNicolantonio http://orcid.org/0000-0002-7888-1528

James OKeefe http://orcid.org/0000-0002-3376-5822

\section{REFERENCES}

1 Venkataraman LV. Spirulina platensis (Arthrospira): physiology, cell biology and Biotechnologym edited by Avigad Vonshak 1997. 
2 Habib MAB. A review on culture, production and use of Spirulina as food for humans and feeds for domestic animals and fish / M. Ahsan B. Habib, Tim C. Huntington, Mohammad R. Hasan. Rome, Italy: Food and Agriculture Organization of the United Nations, 2008.

3 Saklayen MG. The global epidemic of the metabolic syndrome. Curr Hypertens Rep 2018;20:12.

4 Serban M-C, Sahebkar A, Dragan S, et al. A systematic review and meta-analysis of the impact of Spirulina supplementation on plasma lipid concentrations. Clin Nutr 2016;35:842-51.

5 Stepien M, Kujawska-Luczak M, Szulinska M, et al. Beneficia dose-independent influence of Camellia sinensis supplementation on lipid profile, glycemia, and insulin resistance in an $\mathrm{NaCl}$-induced hypertensive rat model. J Physiol Pharmacol 2018;69.

$6 \mathrm{Ng} \mathrm{M}$, Fleming T, Robinson M, et al. Global, regional, and national prevalence of overweight and obesity in children and adults during 1980-2013: a systematic analysis for the global burden of disease study 2013. Lancet 2014;384:766-81.

7 World Health Organization. Global status report on noncommunicable diseases 2014, 2014. Available: https://www.who. int/nmh/publications/ncd-status-report-2014/en/

8 World Health Organization. Obesity and overweight, 2018. Available: https://www.who.int/news-room/fact-sheets/detail/obesity-andoverweight [Accessed 16 Feb 2018].

9 Park HS, Park JY, Yu R. Relationship of obesity and visceral adiposity with serum concentrations of CRP, TNF-alpha and IL-6. Diabetes Res Clin Pract 2005;69:29-35.

10 Shah A, Mehta N, Reilly MP. Adipose inflammation, insulin resistance, and cardiovascular disease. JPEN J Parenter Enteral Nutr 2008;32:638-44

11 Skrypnik K, Suliburska J, Skrypnik D, et al. The genetic basis of obesity complications. Acta Sci Pol Technol Aliment 2017;16:83-91.

12 Terry MJ, Maines MD, Lagarias JC. Inactivation of phytochromeand phycobiliprotein-chromophore precursors by rat liver biliverdin reductase. J Biol Chem 1993;268:26099-106.

13 Zheng J, Inoguchi T, Sasaki S, et al. Phycocyanin and phycocyanobilin from Spirulina platensis protect against diabetic nephropathy by inhibiting oxidative stress. Am J Physiol Regul Integr Comp Physiol 2013;304:R110-20.

14 Strasky Z, Zemankova L, Nemeckova I, et al. Spirulina platensis and phycocyanobilin activate atheroprotective heme oxygenase-1: a possible implication for atherogenesis. Food Funct 2013;4:1586-94.

15 Talior I, Tennenbaum T, Kuroki T, et al. PKC-delta-dependent activation of oxidative stress in adipocytes of obese and insulinresistant mice: role for NADPH oxidase. Am J Physiol Endocrinol Metab 2005;288:E405-11.

16 Furukawa S, Fujita T, Shimabukuro M, et al. Increased oxidative stress in obesity and its impact on metabolic syndrome. J Clin Invest 2004;114:1752-61.

17 Han CY, Umemoto T, Omer M, et al. NADPH oxidase-derived reactive oxygen species increases expression of monocyte chemotactic factor genes in cultured adipocytes. J Biol Chem 2012;287:10379-93.

18 Lin L, Pang W, Chen K, et al. Adipocyte expression of PU.1 transcription factor causes insulin resistance through upregulation of inflammatory cytokine gene expression and ROS production. Am J Physiol Endocrinol Metab 2012;302:E1550-9.

19 Jankovic A, Korac A, Buzadzic B, et al. Redox implications in adipose tissue (dys)function-A new look at old acquaintances. Redox Biol 2015;6:19-32

20 Prokudina ES, Maslov LN, Ivanov VV, et al. [The Role of Reactive Oxygen Species in the Pathogenesis of Adipocyte Dysfunction in Metabolic Syndrome. Prospects of Pharmacological Correction]. Vestn Ross Akad Med Nauk 2017;72:11-16.

21 Yousefi R, Mottaghi A, Saidpour A. Spirulina platensis effectively ameliorates anthropometric measurements and obesity-related metabolic disorders in obese or overweight healthy individuals: a randomized controlled trial. Complement Ther Med 2018;40:106-12.

22 Zeinalian R, Farhangi MA, Shariat A, et al. The effects of Spirulina platensis on anthropometric indices, appetite, lipid profile and serum vascular endothelial growth factor (VEGF) in obese individuals: a randomized double blinded placebo controlled trial. $B M C$ Complement Altern Med 2017;17:225

23 Szulinska M, Gibas-Dorna M, Miller-Kasprzak E, et al. Spirulina maxima improves insulin sensitivity, lipid profile, and total antioxidant status in obese patients with well-treated hypertension: a randomized double-blind placebo-controlled study. Eur Rev Med Pharmacol Sci 2017;21:2473-81.

24 Miczke A, Szulińska M, Hansdorfer-Korzon R, et al. Effects of spirulina consumption on body weight, blood pressure, and endothelial function in overweight hypertensive Caucasians: a double-blind, placebo-controlled, randomized trial. Eur Rev Med Pharmacol Sci 2016;20:150-6.

25 Chen LC, Chen JS, Tung TC. [Effects of spirulina on serum lipoproteins and its hypocholesterolemic activities]. Taiwan Yi Xue Hui Za Zhi 1981;80:934-42.

26 Kato T, Takemoto K, Katayama H, et al. Effects of Spirulina (Spirulin a platensis) on dietary hypercholesterolemia in rats. Nippon Eiyo Shokuryo Gakkaishi 1984;37:323-32.

27 Iwata K, Inayama T, Kato T. Effects of Spirulina platensis on plasma lipoprotein lipase activity in fructose-induced hyperlipidemic rats. $J$ Nutr Sci Vitaminol 1990;36:165-71.

28 Rodríguez-Hernández A, Blé-Castillo JL, Juárez-Oropeza MA, et al. Spirulina maxima prevents fatty liver formation in CD-1 male and female mice with experimental diabetes. Life Sci 2001;69:1029-37.

29 Li T-T, Liu Y-Y, Wan X-Z, et al. Regulatory Efficacy of the Polyunsaturated Fatty Acids from Microalgae Spirulina platensis on Lipid Metabolism and Gut Microbiota in High-Fat Diet Rats. Int J Mol Sci 2018;19. doi:10.3390/ijms19103075. [Epub ahead of print: 09 Oct 2018].

30 Nakaya N, Homma Y, Goto Y. Cholesterol lowering effect of spirulina Nutrition reports international 1988;37:1329-37.

31 Ramamoorthy A, Premakumari S. Effect of supplementation of Spirulina on hypercholesterolemic patients 1996.

32 Mazokopakis EE, Starakis IK, Papadomanolaki MG, et al. The hypolipidaemic effects of Spirulina (Arthrospira platensis) supplementation in a Cretan population: a prospective study. J Sci Food Agric 2014:94:432-7.

33 Panagiotakos DB, Fitzgerald AP, Pitsavos C, et al. Statistical modelling of 10-year fatal cardiovascular disease risk in Greece: the HellenicSCORE (a calibration of the ESC score project). Hellenic J Cardiol 2007;48:55-63.

34 Mani UV, Desai S, lyer U. Studies on the long-term effect of Spirulina supplementation on serum lipid profile and glycated proteins in NIDDM patients. J Diet Suppl 2000;2:25-32.

35 Parikh P, Mani U, lyer U. Role of Spirulina in the control of glycemia and Lipidemia in type 2 diabetes mellitus. J Med Food 2001;4:193-9.

36 Lee EH, Park J-E, Choi Y-J, et al. A randomized study to establish the effects of spirulina in type 2 diabetes mellitus patients. Nutr Res Pract 2008;2:295-300.

37 Samuels R, Mani UV, lyer UM, et al. Hypocholesterolemic effect of spirulina in patients with hyperlipidemic nephrotic syndrome. J Med Food 2002;5:91-6.

38 Castelli WP, Wilson PW, Levy D, et al. Cardiovascular risk factors in the elderly. Am J Cardiol 1989;63:12-19.

39 Kim WY, Park JY. The effects of Spirulina on lipid metabolism, antioxidant capacity and immune function in Korean Elderlies. Korean J Nutr 2003;36:287-97.

$40 \mathrm{Kim}$ WY, Kim MH. The change of lipid metabolism and immune function caused by antioxidant material in the hypercholesterolemic elderly women in Korea. Korean J Nutr 2005;38:67-75.

41 Huang $\mathrm{H}$, Liao D, Pu R, et al. Quantifying the effects of spirulina supplementation on plasma lipid and glucose concentrations, body weight, and blood pressure. Diabetes Metab Syndr Obes 2018;11:729-42.

42 Park HJ, Lee YJ, Ryu HK, et al. A randomized double-blind, placebocontrolled study to establish the effects of spirulina in elderly Koreans. Ann Nutr Metab 2008;52:322-8.

43 Hernández Lepe MA, Wall-Medrano A, Juárez-Oropeza MA, et al. Spirulina and its hypolipidemic and antioxidant effects in humans: a systematic review]. Nutr Hosp 2015;32:494-500.

44 Nagaoka S, Shimizu K, Kaneko H, et al. A novel protein Cphycocyanin plays a crucial role in the hypocholesterolemic action of Spirulina platensis concentrate in rats. J Nutr 2005;135:2425-30.

45 Piñero Estrada JE, Bermejo Bescós P, Villar del Fresno AM. Antioxidant activity of different fractions of Spirulina platensis protean extract. Farmaco 2001;56:497-500.

46 Han L-K, Li D-X, Xiang L, et al. [Isolation of pancreatic lipase activity-inhibitory component of spirulina platensis and it reduce postprandial triacylglycerolemia]. Yakugaku Zasshi 2006;126:43-9.

47 Hornych A, Oravec S, Girault F, et al. The effect of gamma-linolenic acid on plasma and membrane lipids and renal prostaglandin synthesis in older subjects. Bratis/ Lek Listy 2002;103:101-7.

48 Horrobin DF. Nutritional and medical importance of gamma-linolenic acid. Prog Lipid Res 1992;31:163-94.

49 Zeb Shah T, Ali AB, Ahmad Jafri S, et al. Effect of Nicotinic Acid (Vitamin B3 or Niacin) on the lipid profile of diabetic and non diabetic rats. Pak J Med Sci 2013;29:1259-64. 